\title{
Optimization of Strength, Ductility and Corrosion Resistance in Ti-Mo Base Alloys by Controlling Mo Equivalency and Bond Order
}

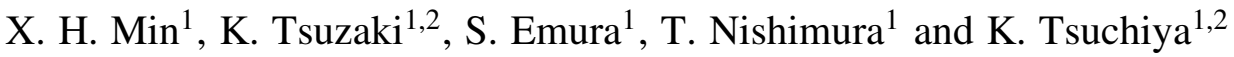 \\ ${ }^{1}$ National Institute for Materials Science, Tsukuba 305-0047, Japan \\ ${ }^{2}$ Graduate School of Pure and Applied Sciences, University of Tsukuba, Tsukuba 305-0047, Japan
}

\begin{abstract}
The crevice corrosion resistance in high chloride and high acidic solution at high temperature in Ti- $15 \mathrm{Mo}-5 \mathrm{Zr}$ and $\mathrm{Ti}-15 \mathrm{Mo}-5 \mathrm{Zr}-1 \mathrm{Fe}$ alloys and the tensile properties at ambient temperature in Ti-15Mo-5Zr-1Fe alloy were investigated in this study. The crevice corrosion resistance in Ti-15Mo-5Zr alloy with a Mo equivalency of 18.2 mass $\%$, which was previously reported to show a combination of the high yield strength and the significant uniform elongation, was almost twice as high as that in Ti-15Mo alloy when the bond order (Bo) increased from 2.8126 to 2.8232 . A linear correlation between the crevice corrosion resistance and the Bo was confirmed in the Ti-Mo base alloys with the Bo between 2.7900 and 2.8232. Although the high crevice corrosion resistance, Ti-15Mo-5Zr-1Fe alloy with a Mo equivalency of 21.2 mass $\%$ showed high yield strength but negligible uniform elongation due to the deformation by dislocation slip. This study suggested that the two parameters of the Mo equivalency and the Bo are useful for an optimization of strength, ductility and corrosion resistance in Ti-Mo base alloys. [doi:10.2320/matertrans.M2011124]
\end{abstract}

(Received April 22, 2011; Accepted May 25, 2011; Published July 13, 2011)

Keywords: beta titanium alloy, phase stability, bond order, tensile property, corrosion resistance

\section{Introduction}

Titanium and its alloys are widely used as the structural materials due to their good mechanical properties and high corrosion resistance. However, they are susceptible to corrosion attack when exposed to highly acidic environments at high temperature. ${ }^{1,2)}$ To overcome this drawback, enhancement of the stability of the surface oxide film has been paid much attention through adding the noble alloying elements such as $\mathrm{Pd}$ and $\mathrm{Ru}{ }^{3-5)}$ Meanwhile, it has been reported that titanium alloys with sufficient content of Mo provides the high corrosion resistance. ${ }^{6-9)}$

Nishimura $^{8)}$ found that a Ti-15Mo alloy (mass $\%$ ), which was developed in the 1950s as a corrosion resistance $\beta$ titanium alloy, ${ }^{10)}$ exhibits an extremely high corrosion resistance in highly acidic solution at $373 \mathrm{~K}$, which is able to against the crevice corrosion in seawater at the high temperature. However, this alloy shows a low yield strength in the as-solution treated condition because of its deformation by $\{332\}\langle 113\rangle$ twinning. ${ }^{11,12)}$ If the yield strength of this alloy can be improved along with its high corrosion resistance, it will be a desirable structural material using in sever corrosion environments such as chemical plants, oil well tubes and offshore structures instead of $\mathrm{Ru}$ - or Pd-bearing titanium alloys.

It is well known that the tensile properties of $\beta$ titanium alloys depend significantly on the deformation modes, ${ }^{13-15)}$ i.e. $\{332\}\langle 113\rangle$ twinning and dislocation slip, which are sensitive to the $\beta$ phase stability. The twinning occurs in the alloys with low phase stability and leads to the low yield strength and large uniform elongation, while the slip occurs in the alloys with high phase stability and leads to the high yield strength and negligible uniform elongation. From an engineering point of view, a coexistence of high strength and large uniform elongation is crucial to ensure good formability under complex loading conditions.

In the previous study, the present authors ${ }^{16)}$ found that a combination of the above-mentioned twinning and slip

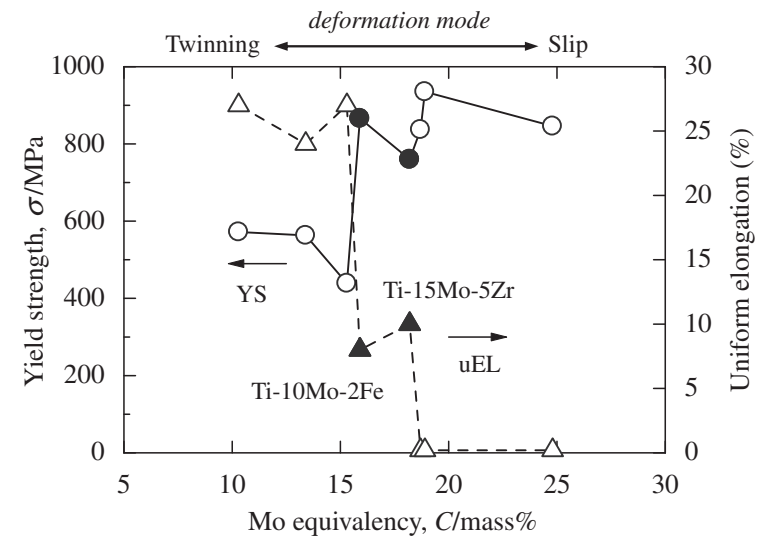

Fig. 1 Changes in the yield strength (YS) and the uniform elongation (uEL) against the Mo equivalency in Ti-Mo base alloys, ${ }^{16)}$ showing that a combination of high strength and significant elongation can be achieved at the Mo equivalency between 15.3 and 18.7 mass\% (solid marks).

deformation modes is an effective for achieving the high yield strength and large uniform elongation in Ti-10Mo-2Fe and Ti-15Mo-5Zr alloys among Ti-Mo base alloys as shown in Fig. 1, where the Mo equivalency was designed to be between 15.3 and 18.7 mass\%. Note that the Mo equivalency, which is the ratio of the level of a given stabilizer to the one of Mo required for the same degree of $\beta$ phase stability, is useful parameter for evaluating the $\beta$ phase stability. ${ }^{17-19)}$

On the other hand, the corrosion resistance of titanium alloys is affected by various factors such as chemical composition and microstructure. ${ }^{20-23)}$ Morishita et al. ${ }^{20)}$ investigated the effects of alloying elements on the corrosion resistance of various kinds of $\beta$ titanium alloys in both $10 \% \mathrm{HCl}$ and $10 \% \mathrm{H}_{2} \mathrm{SO}_{4}$, and concluded that the alloys containing the elements with the higher bond order (Bo) showed the lower active corrosion rate. Note that the Bo is a measure of the covalent bond strength between the titanium and the alloying element. ${ }^{24,25)}$ Matsugi et al ${ }^{26)}$ reported that a ratio of weight loss to initial weight obtained from the 


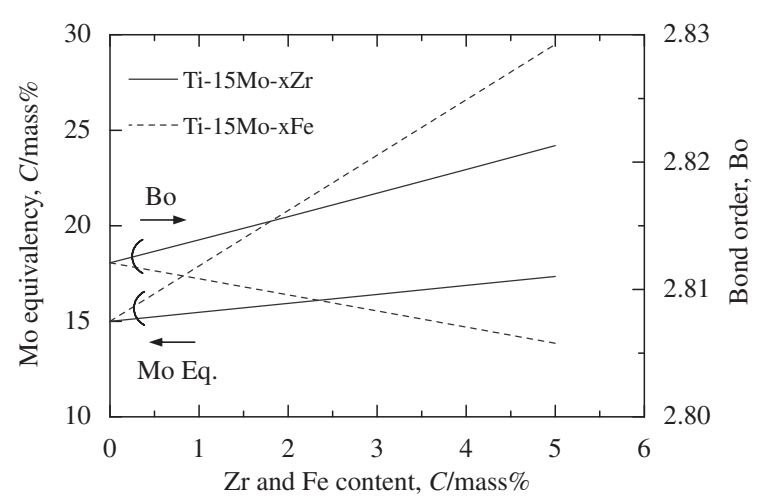

Fig. 2 Changes in the Mo equivalency (Eq.) and the bond order (Bo) with content of $\mathrm{Zr}$ and $\mathrm{Fe}$ in Ti-15Mo alloy.

immersion test for $21.6 \mathrm{ks}$ in $\mathrm{Na}_{2} \mathrm{SO}_{4}-\mathrm{NaCl}$ molten salt at $923 \mathrm{~K}$ decreases with increasing the Bo in some $\alpha+\beta$ and $\beta$ titanium alloys. These results indicated that an increase in the covalent bond strength between the atoms, i.e. an increase in the Bo, leads to high corrosion resistance of the titanium alloys. In addition, the present authors ${ }^{27,28)}$ reported that the corrosion resistance of Ti-10Mo and Ti-15Mo alloys in the highly acidic solution at high temperature deteriorates by $\mathrm{Fe}$ addition, which is interpreted in terms of the Bo between 2.7900 and 2.8126. Although Ti-15Mo alloy with the Bo of 2.8126 exhibits the high crevice corrosion resistance, the alloy with the higher corrosion resistance is desirable to achieve on the basis of the Bo. Thus, the correlation between the corrosion resistance and the Bo is needed to further confirm in the alloy with a larger range value of the Bo.

Therefore, both of the Mo equivalency and the Bo should be considered to design the alloy for an optimization of strength, ductility and corrosion resistance. As shown in Fig. 2, the Mo equivalency increases by $\mathrm{Zr}$ and Fe addition in Ti-15Mo alloy. Meanwhile, the Bo increases by $\mathrm{Zr}$ addition in the alloy, while it decreases by $\mathrm{Fe}$ addition. Note that the Bo value for $\mathrm{Ti}, \mathrm{Mo}, \mathrm{Zr}$ and $\mathrm{Fe}$ in bec $\mathrm{Ti}$ is 2.790, 3.063, 3.086 and 2.651, respectively. Although Ti-15Mo-5Zr alloy with a Mo equivalency of 18.2 mass \% shows the high yield strength of $760 \mathrm{MPa}$ and significant uniform elongation of $10 \%$ as mentioned before, ${ }^{16)}$ the change in the crevice corrosion resistance has not been investigated in the case of an increase in the Bo of 2.8232, which is determined as the atomic compositional average of above-mentioned Bo values on the basis of the analyzed chemical compositions. In addition, the tensile property of the alloy with the larger Bo is needed to further confirm when the Mo equivalency is larger than that of 18.7 mass\% as shown in Fig. 1. Thus, Ti-15Mo-5Zr-1Fe alloy is also selected for this study with a Mo equivalency of 21.2 mass $\%$ and a Bo of 2.8209, which will be shown later (Table 3 ).

The aim of this study is to investigate the corrosion resistance in high chloride and high acidic solution at high temperature in $\mathrm{Ti}-15 \mathrm{Mo}-5 \mathrm{Zr}$ and $\mathrm{Ti}-15 \mathrm{Mo}-5 \mathrm{Zr}-1 \mathrm{Fe}$ alloys and the tensile property at ambient temperature in Ti-15Mo$5 \mathrm{Zr}-1 \mathrm{Fe}$ alloy, and to discuss an effectiveness for optimizing the strength, ductility and corrosion resistance by controlling the Mo equivalency and the bond order.

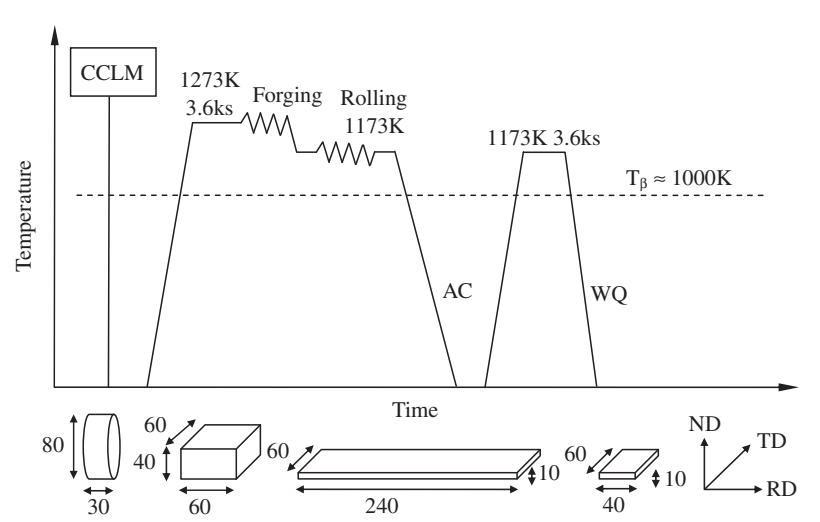

Fig. 3 A schematic drawing of heat treatment of Ti-15Mo-5Zr and Ti-15Mo-5Zr-1Fe alloys. CCLM, AC and WQ refer to cold crucible levitation melting, air cooling and water quenching, respectively.

Table 1 Nominal and analyzed chemical compositions of Ti-15Mo-5Zr and Ti-15Mo-5Zr-1Fe alloys along with Ti-15Mo and Ti-15Mo-1Fe alloys (mass\%).

\begin{tabular}{lccccccc}
\hline \multicolumn{1}{c}{ Alloys } & Mo & $\mathrm{Zr}$ & $\mathrm{Fe}$ & $\mathrm{O}$ & $\mathrm{N}$ & $\mathrm{C}$ & $\mathrm{Ti}$ \\
\hline Ti-15Mo-5Zr & 15.7 & 5.36 & - & 0.103 & 0.004 & 0.008 & Bal. \\
Ti-15Mo-5Zr-1Fe & 15.2 & 5.42 & 1.20 & 0.091 & 0.004 & 0.009 & Bal. \\
Ti-15Mo & 15.3 & - & - & 0.105 & 0.004 & 0.012 & Bal. \\
Ti-15Mo-1Fe & 15.3 & - & 1.16 & 0.092 & 0.005 & 0.008 & Bal. \\
\hline
\end{tabular}

\section{Experimental}

\subsection{Materials preparation}

Ti-15Mo-5Zr and Ti-15Mo-5Zr-1Fe alloys along with Ti$15 \mathrm{Mo}$ and $\mathrm{Ti}-15 \mathrm{Mo}-1 \mathrm{Fe}$ alloys ${ }^{27)}$ as the reference alloys were prepared by cold crucible levitation melting. Each ingot had $80 \mathrm{~mm}$ in diameter and $30 \mathrm{~mm}$ in length. Figure 3 shows a schematic drawing of the heat treatment for these alloys. The ingots were homogenized at $1273 \mathrm{~K}$ for $3.6 \mathrm{ks}$, hot forged at $1273 \mathrm{~K}$ into blocks of $60 \mathrm{~mm}(l) \times 60 \mathrm{~mm}(w) \times 40 \mathrm{~mm}(t)$, and then hot rolled into plates of $240 \mathrm{~mm}(l) \times 60 \mathrm{~mm}$ $(w) \times 10 \mathrm{~mm}(t)$ at $1173 \mathrm{~K}$ followed by air cooling. The plates were cut into $40 \mathrm{~mm}(l) \times 60 \mathrm{~mm}(w) \times 10 \mathrm{~mm}(t)$ pieces and were solution treated at $1173 \mathrm{~K}$ for $3.6 \mathrm{ks}$ followed by water quenching. The heat treatments were carried out in the air. The principal axes of the rolled specimens corresponding to normal direction (ND), rolling direction (RD) and transverse direction (TD) are defined as shown in Fig. 3. The analyzed chemical compositions of the alloys after the solution treatment are listed in Table 1.

\subsection{Microstructural characterization}

The specimens were mechanically polished and etched by using a solution of distilled water, nitric acid and hydrofluoric acid (100:3:2 in volume) and then observed by an optical microscope (OM). Transmission electron microscope (TEM) observations were performed by a JEOL-2000FX system operating at $200 \mathrm{kV}$. Thin foils were prepared by a twin-jet electro-polisher in a solution of methanol, 1-butanol and perchloric acid (10:6:1 in volume) at $228 \mathrm{~K}$ with a voltage of $20 \mathrm{~V}$. A field emission scanning electron microscope (FESEM) equipped with an orientation imaging microscope was employed to conduct the electron backscattered diffraction 
(EBSD) analysis with a step size of $1 \mu \mathrm{m}$ performed on a JSM-7001F system.

\subsection{Corrosion test}

The specimens were cut into $10 \mathrm{~mm}(l) \times 10 \mathrm{~mm}(w) \times$ $2 \mathrm{~mm}(t)$ pieces along the RD and TD of the plates for the corrosion test. The corrosion resistance was evaluated by using the electrochemical impedance spectroscopy (EIS). The EIS measurements were carried out in a water solution of $10 \% \mathrm{NaCl}$ with a $\mathrm{pH}$ value of 0.5 at $370 \mathrm{~K}$ (hereafter referred to as the simulated crevice solution), which was used to simulate the crevice inner solution with high chloride and low $\mathrm{pH}$. Note that the highest temperature of the solution in chemical plants is usually around $373 \mathrm{~K}$ because of the boiling point of the solution, specially the seawater. A platinum counter electrode and a saturated calomel reference electrode (SCE) were used to carry out the EIS measurements. The specimens used as the working electrodes were covered with epoxy resin, and then mechanically polished so that only one metal surface would be in contact with the simulated crevice solution after deaeration by argon gas. A frequency response analyzer (FRA) was used for the EIS measurements with an amplitude of $10 \mathrm{mV}$ and a frequency range of $0.003 \mathrm{~Hz}$ to $20 \mathrm{kHz}$. The electrochemical impedance spectra were obtained in an open circuit potential (OCP) condition after the specimens were immersed into the simulated crevice solution at $370 \mathrm{~K}$ for $1.8 \mathrm{ks}$ to reach the steady state condition.

\subsection{Tensile test}

The tensile specimens with a width of $4 \mathrm{~mm}$ and a thickness of $2 \mathrm{~mm}$ in the gage section with a length of $18 \mathrm{~mm}$ were cut by electric discharge machining along the RD and TD of the plates. The tensile tests were carried out at ambient temperature with a cross-head speed of $5 \times 10^{-3} \mathrm{~mm} \mathrm{~s}^{-1}$.

\section{Results}

\subsection{Microstructure}

Figure 4 shows the optical micrographs of Ti-15Mo-5Zr and $\mathrm{Ti}-15 \mathrm{Mo}-5 \mathrm{Zr}-1 \mathrm{Fe}$ alloys. The OM observations revealed that both alloys consist of $\beta$ phase with an average grain size of $100 \mu \mathrm{m}$, which is no significant difference compared to that of Ti-15Mo and Ti-15Mo-1Fe alloys. ${ }^{28)}$ Figure 5 shows the selected area diffraction (SAD) patterns. The presences of the $\beta$ phase are confirmed in both alloys. In addition, the diffraction spots for the athermal $\omega$ phase are clearly detected in Ti-15Mo-5Zr alloy as shown in Fig. 5(a), while it becomes weaker and diffuse in Ti-15Mo-5Zr-1Fe alloys in Fig. 5(b). This difference in the athermal $\omega$ phase between the alloys is caused by the different $\beta$ phase stability. Here, it should be emphasized that the effect of the athermal $\omega$ phase on the corrosion resistance is thought to be small as mentioned in the previous study ${ }^{27)}$ since the chemical compositions of the athermal $\omega$ phase are the same as that of the $\beta$ phase.

\subsection{Crevice corrosion resistance}

Figure 6 shows the electrochemical impedance spectra of Ti-15Mo-5Zr and Ti-15Mo-5Zr-1Fe alloys along with Ti-15Mo and Ti-15Mo-1Fe alloys and commercially pure
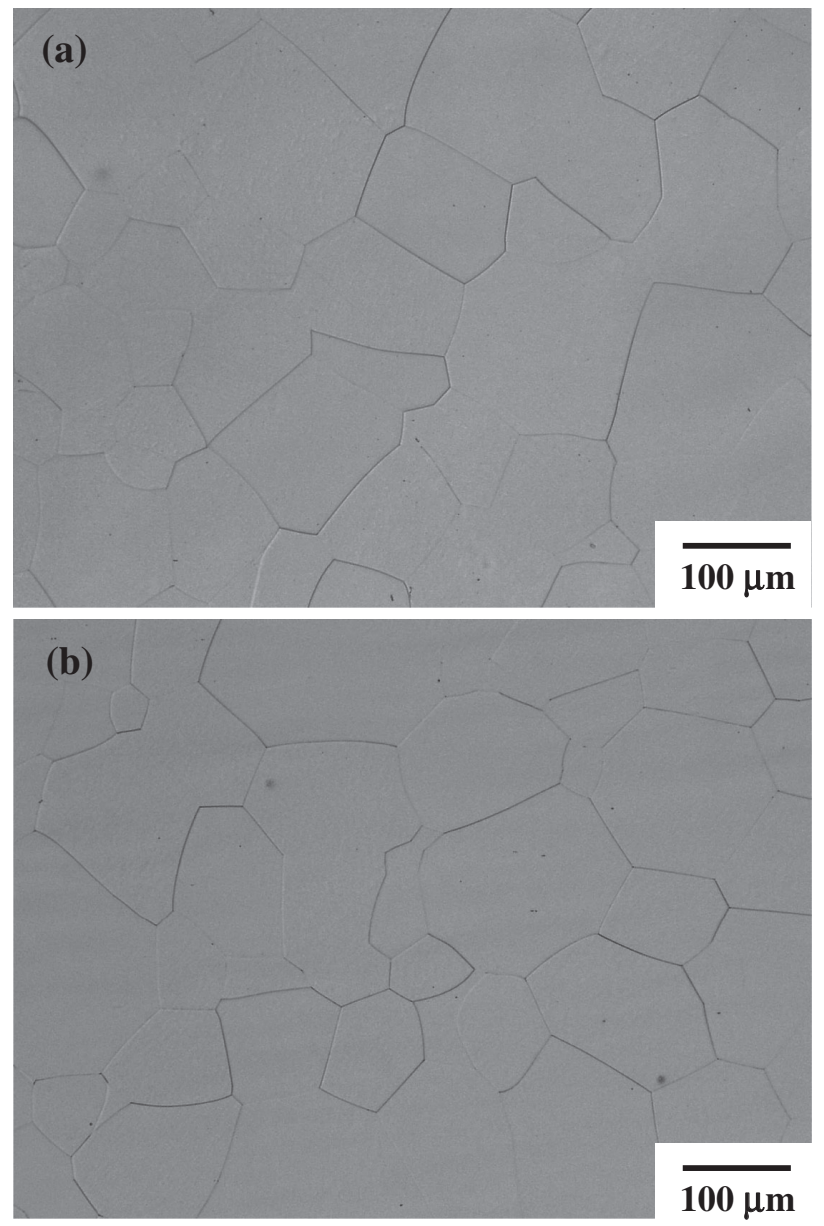

Fig. 4 Optical micrographs of (a) Ti-15Mo-5Zr alloy and (b) Ti-15Mo$5 \mathrm{Zr}-1 \mathrm{Fe}$ alloy.

titanium Grade 2 (CP Ti). The electrochemical impedance spectra are used to investigate the effect of alloying elements on the corrosion resistance of the passive film against the crevice attack. Figure 6(a) and (b) shows the changes in the impedance and the phase angle with the frequency, respectively. Each spectrum of Ti-15Mo-5Zr and Ti-15Mo$5 \mathrm{Zr}-1 \mathrm{Fe}$ alloys like those of $\mathrm{Ti}-15 \mathrm{Mo}$ and $\mathrm{Ti}-15 \mathrm{Mo}-1 \mathrm{Fe}$ alloys indicates two corrosion resistance components and one capacitance component. As shown in Fig. 6(a), the impedance in the high frequency region from 1 to $20 \mathrm{kHz}$ reflects the solution resistance, and the one in the low frequency region from 0.003 to $0.01 \mathrm{~Hz}$ reflects the passive film resistance. ${ }^{8)}$ On the basis of Fig. 6(b), the spectrum of Ti$15 \mathrm{Mo}-5 \mathrm{Zr}$ and $\mathrm{Ti}-15 \mathrm{Mo}-5 \mathrm{Zr}-1 \mathrm{Fe}$ alloys shows one capacitance at around $30 \mathrm{~Hz}$, while the one of the CP Ti shows two capacitances at around $0.06 \mathrm{~Hz}$ and $30 \mathrm{~Hz}$, respectively. Note that the capacitance in the high frequency region at around $30 \mathrm{~Hz}$ is the passive film capacitance, and the one in the low frequency region at around $0.06 \mathrm{~Hz}$ is the double layer capacitance, which corresponds to the active condition. ${ }^{8)}$ The high impedance value in the low frequency region and the passive film capacitance indicate that the alloys are passivated and exhibit the high corrosion resistance under the severe environment of high chloride and high acidic solution at high temperature; however, the active dissolution of the $\mathrm{CP}$ Ti occurs under the same environment. 

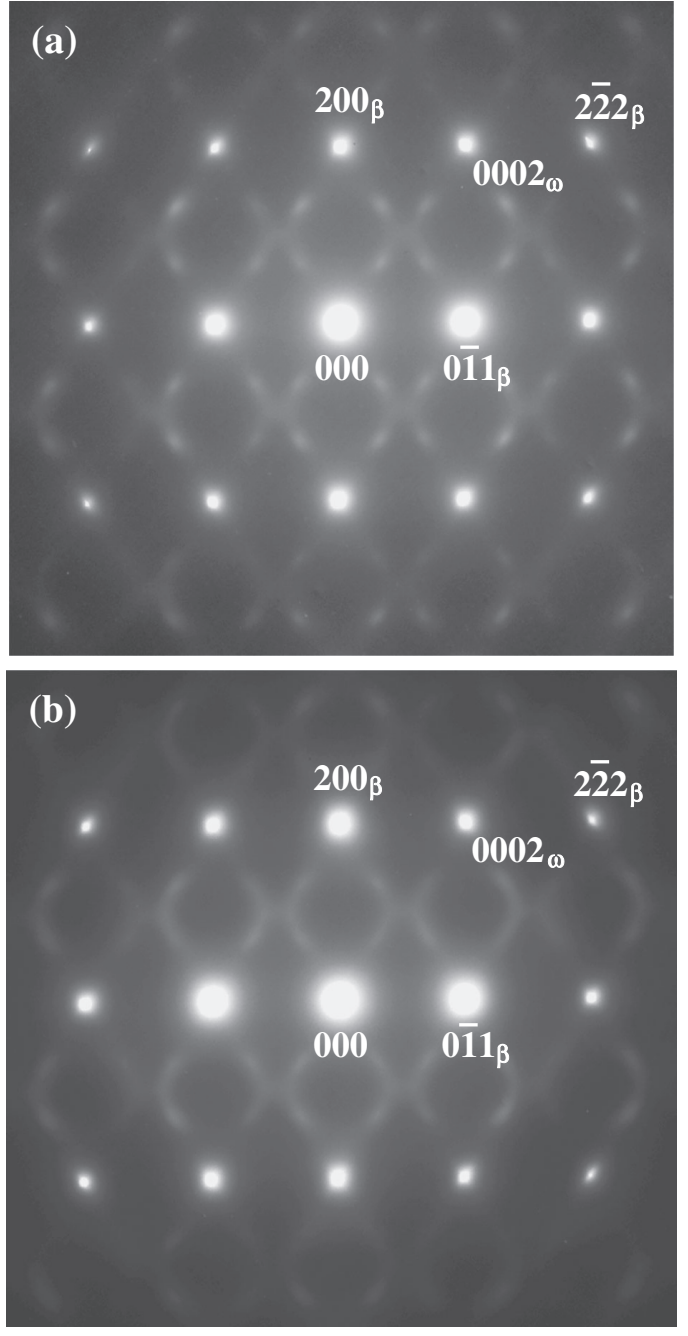

Fig. 5 Selected area diffraction patterns of (a) Ti-15Mo-5Zr alloy and (b) Ti-15Mo-5Zr-1Fe alloy. The zone axis is parallel to $[011]_{\beta}$.

Although all the alloys can be kept in the passive state, the different impedance values in the low frequency region as shown in Fig. 6(a) indicate that the alloying elements affect the corrosion resistance. Note that the higher impedance indicates that the passive film formed on the alloy is more stable and the alloy has the higher corrosion resistance. To evaluate the difference quantitatively, the average impedance was obtained for each alloy in a low frequency region from 0.003 to $0.01 \mathrm{~Hz}$ and listed in Table 2. The Ti-15Mo- $5 \mathrm{Zr}$ and $\mathrm{Ti}-15 \mathrm{Mo}-5 \mathrm{Zr}-1 \mathrm{Fe}$ alloys exhibit higher impedance of 3584 and $3482 \Omega \mathrm{cm}^{2}$, respectively, than that of 2029 and $1785 \Omega \mathrm{cm}^{2}$ in $\mathrm{Ti}-15 \mathrm{Mo}$ and $\mathrm{Ti}-15 \mathrm{Mo}-1 \mathrm{Fe}$ alloys, respectively. The Ti-15Mo-5Zr alloy shows the highest value among the alloys.

Figure 7 shows that the change in the average impedance against the Bo in Ti-15Mo base alloys along with the CP Ti. Since the largest Bo of 2.8232 among the alloys, Ti-15Mo-5Zr alloy shows the highest corrosion resistance. In addition, the Ti-15Mo-5Zr-1Fe alloy shows the higher corrosion resistance since the Bo of 2.8209 is larger than that of 2.8126 in $\mathrm{Ti}-15 \mathrm{Mo}$ alloy, although the corrosion resistance is slightly lower than that of $\mathrm{Ti}-15 \mathrm{Mo}-5 \mathrm{Zr}$ alloy.
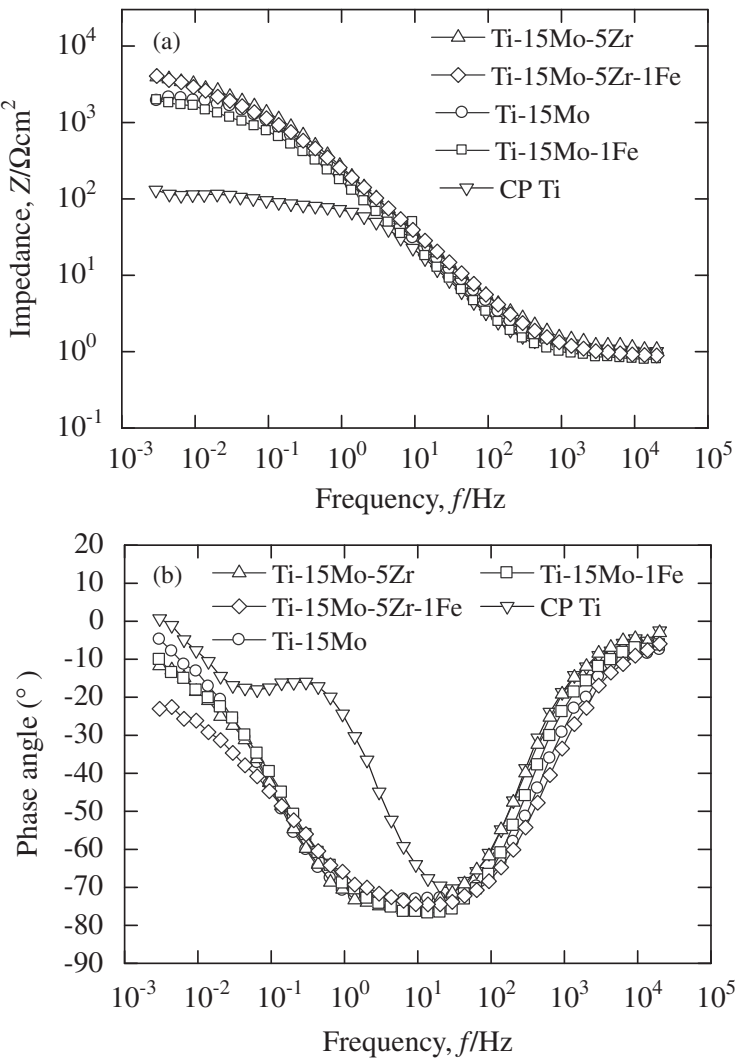

Fig. 6 Electrochemical impedance spectra of Ti-15Mo-5Zr and Ti-15Mo$5 \mathrm{Zr}-1 \mathrm{Fe}$ alloys along with $\mathrm{Ti}-15 \mathrm{Mo}$ and $\mathrm{Ti}-15 \mathrm{Mo}-1 \mathrm{Fe}$ alloys and the commercially pure titanium Grade $2(\mathrm{CP} \mathrm{Ti})^{27)}$ at an open circuit potential condition in a water solution of $10 \% \mathrm{NaCl}$ with a $\mathrm{pH}$ value of 0.5 at $370 \mathrm{~K}$. (a) impedance and (b) phase angle.

Table 2 Corrosion resistance for the average impedance $\left(R_{\mathrm{t}}\right)$ in a low frequency region from 0.003 to $0.01 \mathrm{~Hz}$, and tensile properties for $0.2 \%$ proof stress (YS), tensile strength (TS), uniform elongation (uEL) and total elongation (tEL) in Ti-15Mo base alloys and the commercially pure titanium Grade 2 (CP Ti).

\begin{tabular}{lcccccc}
\hline \multicolumn{1}{c}{ Alloys } & $\begin{array}{c}R_{\mathrm{t}} \\
\left(\Omega \mathrm{cm}^{2}\right)\end{array}$ & $\begin{array}{c}\text { YS } \\
(\mathrm{MPa})\end{array}$ & $\begin{array}{c}\text { TS } \\
(\mathrm{MPa})\end{array}$ & $\begin{array}{c}\mathrm{uEL} \\
(\%)\end{array}$ & $\begin{array}{c}\text { tEL } \\
(\%)\end{array}$ & Ref. \\
\hline Ti-15Mo-5Zr & 3584 & 760 & 801 & 10 & 19 & \\
Ti-15Mo-5Zr-1Fe & 3482 & 800 & 800 & 0.2 & 21 & \\
Ti-15Mo & 2029 & 439 & 714 & 27 & 49 & $28)$ \\
Ti-15Mo-1Fe & 1785 & 837 & 837 & 0.2 & 19 & $28)$ \\
CP Ti & 111 & 275 & 345 & - & 20 & $28)$ \\
\hline
\end{tabular}

\subsection{Tensile property}

Figure 8 shows the nominal stress-strain curves of Ti$15 \mathrm{Mo}-5 \mathrm{Zr}-1 \mathrm{Fe}$ alloy along with $\mathrm{Ti}-15 \mathrm{Mo}-5 \mathrm{Zr}$ alloy. Although the flow stress level is similar, Ti-15Mo-5Zr-1Fe alloy exhibits a significantly different shape of the stressstrain curve compared to that of Ti-15Mo-5Zr alloy. Table 2 lists the tensile properties of $0.2 \%$ proof stress (YS), tensile strength (TS), uniform elongation (uEL), total elongation (tEL) for Ti-15Mo base alloys and the CP Ti. The Ti-15Mo$5 \mathrm{Zr}-1 \mathrm{Fe}$ alloy shows a high yield strength of $800 \mathrm{MPa}$ and a large total elongation of $21 \%$, which are comparable to those of Ti-15Mo-5Zr alloy. On the other hand, Ti-15Mo$5 \mathrm{Zr}-1 \mathrm{Fe}$ alloy shows the uniform elongation of almost $0 \%$ 


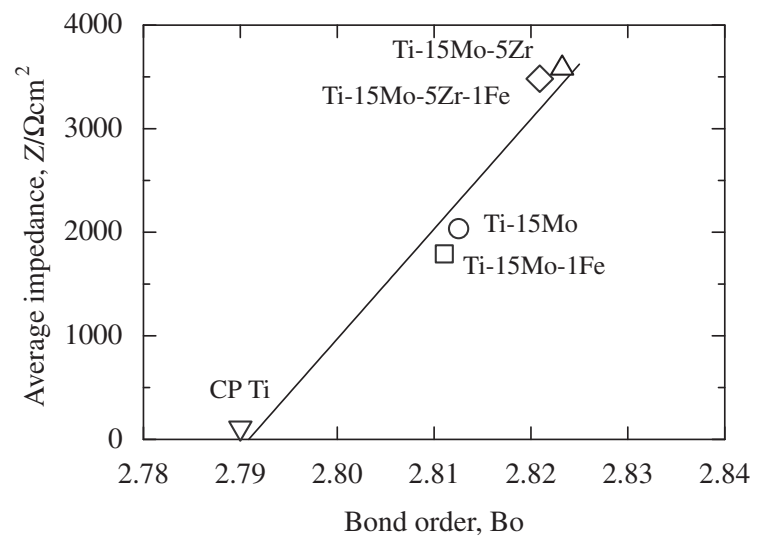

Fig. 7 Change in the average impedance in a low frequency region from 0.003 to $0.01 \mathrm{~Hz}$ against the bond order (Bo) in Ti-15Mo base alloys and the commercially pure titanium Grade 2 (CP Ti).

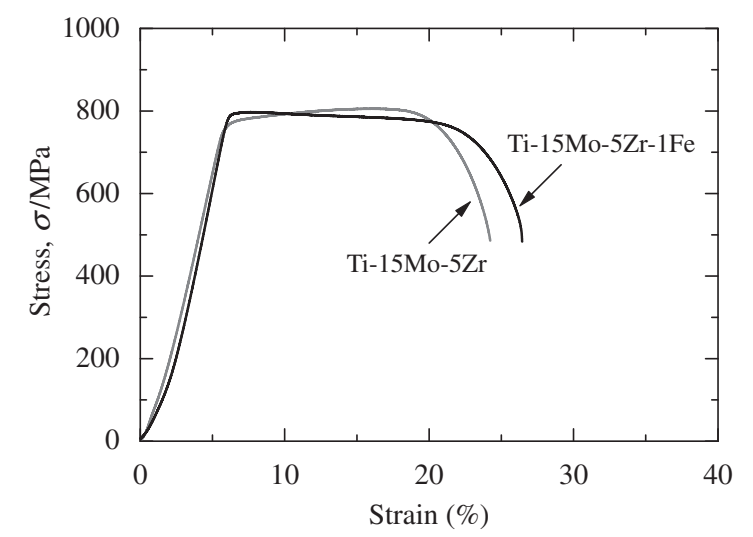

Fig. 8 Nominal stress-strain curves of Ti-15Mo-5Zr-1Fe alloy along with Ti-15Mo-5Zr alloy.

like Ti-15Mo-1Fe alloy, while Ti-15Mo-5Zr alloy has the value of $10 \%$.

Figure 9 shows the microstructures of the specimen after being deformed to a tensile strain of $4.0 \%$ in Ti-15Mo-5Zr1Fe alloy. As shown in Fig. 9(a), the slip traces are clearly observed in the grains without the $\{332\}\langle 113\rangle$ twins from the optical observation. The EBSD inverse pole figure further confirms that the mechanical twins are absent in this alloy as shown in Fig. 9(b). These results indicate that the deformation in Ti-15Mo-5Zr-1Fe alloy is dominated by the dislocation slip to result in the high strength and negligible uniform elongation like previously reported in Ti-15Mo-1Fe, Ti$10 \mathrm{Mo}-3 \mathrm{Fe}$ and Ti-10Mo-5Fe alloys. ${ }^{27,28)}$

\section{Discussion}

The previous studies ${ }^{27,28)}$ investigated the crevice corrosion resistance in the high chloride and high acidic solution at high temperature in Ti-10Mo and Ti-15Mo alloys with Fe addition, and found that the corrosion resistance decreases with decreasing the Bo when the Bo is between 2.7987 and 2.8126 as shown in Table 3 . This study further investigated the corrosion resistance in $\mathrm{Ti}-15 \mathrm{Mo}-5 \mathrm{Zr}$ and $\mathrm{Ti}-15 \mathrm{Mo}-5 \mathrm{Zr}-$ $1 \mathrm{Fe}$ alloys with the larger Bo from 2.8126 to 2.8232 , and
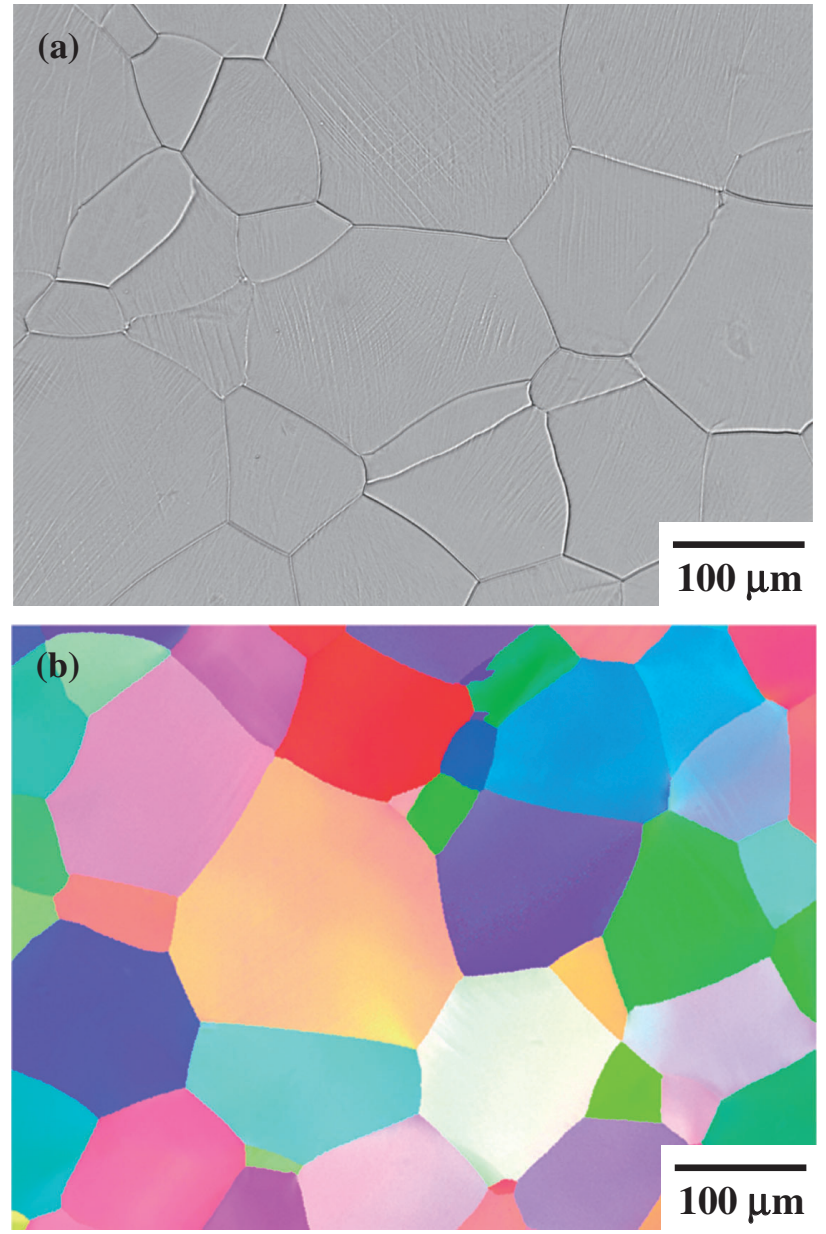

Fig. 9 Microstructures of the specimen after being deformed to a tensile strain of $4.0 \%$ in Ti-15Mo-5Zr-1Fe alloy. (a) optical micrograph and (b) EBSD inverse pole figure for the ND. The tensile axis is the horizontal direction parallel to the RD and the observed plane is normal to the ND.

Table 3 Calculated Mo equivalency (Eq.) and bond order (Bo) by the analyzed chemical compositions, $0.2 \%$ proof stress (YS), uniform elongation (uEL) and normalized impedance $\left(\mathrm{n} R_{\mathrm{t}}\right)$ in Ti-Mo base alloys along with the commercially pure titanium Grade 2 (CP Ti).

\begin{tabular}{lcccccc}
\hline \multicolumn{1}{c}{ Alloys } & $\begin{array}{c}\text { Mo Eq. } \\
(\text { mass\% })\end{array}$ & Bo & $\begin{array}{c}\text { YS } \\
(\mathrm{MPa})\end{array}$ & $\begin{array}{c}\mathrm{uEL} \\
(\%)\end{array}$ & $\mathrm{n} R_{\mathrm{t}}$ & Ref. \\
\hline Ti-15Mo-5Zr & 18.2 & 2.8232 & 760 & 10 & 1.767 & \\
Ti-15Mo-5Zr-1Fe & 21.2 & 2.8209 & 800 & 0.2 & 1.716 & \\
Ti-15Mo & 15.3 & 2.8126 & 439 & 27 & 1 & $28)$ \\
Ti-15Mo-1Fe & 18.7 & 2.8111 & 837 & 0.2 & 0.880 & $28)$ \\
Ti-10Mo & 10.3 & 2.8048 & 572 & 27 & 0.607 & $27)$ \\
Ti-10M-1Fe & 13.4 & 2.8037 & 563 & 24 & 0.606 & $27)$ \\
Ti-10Mo-2Fe & 15.9 & 2.8020 & 866 & 8 & - & $16)$ \\
Ti-10Mo-3Fe & 18.9 & 2.8015 & 935 & 0.2 & 0.573 & $27)$ \\
Ti-10Mo-5Fe & 24.8 & 2.7987 & 846 & 0.2 & 0.566 & $27)$ \\
CP Ti & - & 2.7900 & 275 & - & 0.055 & $28)$ \\
\hline
\end{tabular}

found that corrosion resistance increases with increasing the Bo.

Note that a direct comparison of the corrosion resistance becomes difficult between Ti-15Mo base alloys and Ti-10Mo base alloys since the measured impedance by the EIS is sensitively affected by many factors such as different 


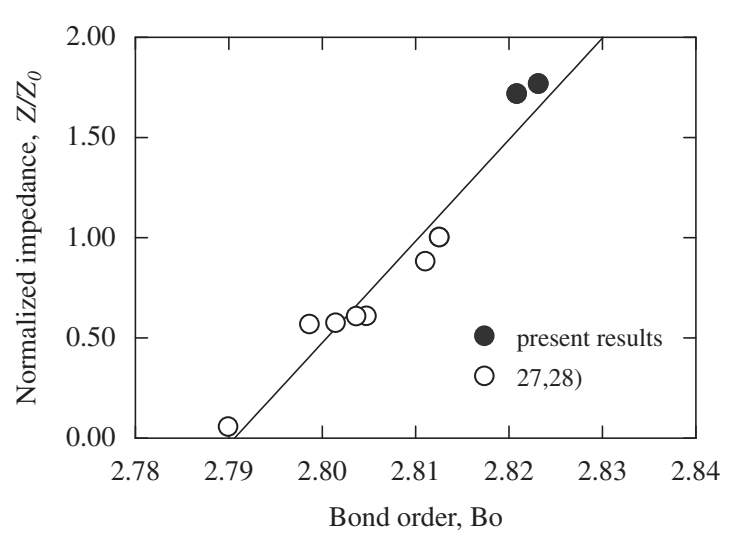

Fig. 10 Change in the normalized impedance $\left(\mathrm{Z} / \mathrm{Z}_{0}\right)$ against the bond order $(\mathrm{Bo})$. $\mathrm{Z}$ and $\mathrm{Z}_{0}$ are the average impedance in a low frequency region from 0.003 to $0.01 \mathrm{~Hz}$ in Ti-Mo base alloys and Ti-15Mo alloy, respectively.

solution, measurement condition. Here, it is needed to emphasis that Ti-15Mo alloy as a reference material was used not only for experimental series of Ti-15Mo base alloys but also for the one of Ti-10Mo base alloys. Therefore, in the present study, the average impedance of each alloy in a low frequency region from 0.003 to $0.01 \mathrm{~Hz}$ was normalized by that of Ti-15Mo alloy. Table 3 provides the normalized impedance of the alloys. Figure 10 shows the change in the normalized impedance against the Bo. Consequently, a linear correlation between the corrosion resistance and the Bo is obtained in the alloys with a large range value of the Bo between 2.7900 and 2.8232. In addition, when the Bo increases from 2.8126 to 2.8232 , the corrosion resistance in $\mathrm{Ti}-15 \mathrm{Mo}-5 \mathrm{Zr}$ alloy is almost twice as high as that in Ti-15Mo alloy.

On the other hand, the present authors ${ }^{16)}$ reported that the change in the tensile properties in Ti-Mo base alloys with the Mo equivalency from 10.3 to 24.8 mass\% (Table 3 ), and found that a combination of high yield strength and significant uniform elongation can be achieved when the Mo equivalency is between 15.3 and 18.7 mass\% as shown in Fig. 1. This study further confirmed the tensile properties when the Mo equivalency is larger than 18.7 mass \%, i.e. high strength and negligible uniform elongation, by using Ti$15 \mathrm{Mo}-5 \mathrm{Zr}-1 \mathrm{Fe}$ alloy. Although the high corrosion resistance and high yield strength, Ti-15Mo-5Zr-1Fe alloy shows the negligible uniform elongation. As mentioned in Section 1, Ti-15Mo alloy shows the high corrosion resistance and large uniform elongation, but the low yield strength. In addition, Ti-10Mo-2Fe alloy shows a combination of high yield strength and significant uniform elongation, ${ }^{16)}$ while its corrosion resistance could be lower than that in Ti-15Mo alloy, although the corrosion test was not carried out. Here, it is should be emphasized that $\mathrm{Ti}-15 \mathrm{Mo}-5 \mathrm{Zr}$ alloy shows the high yield strength, significant uniform elongation and high corrosion resistance. Therefore, two parameters of the Mo equivalency and the Bo would be useful to optimize the strength, ductility and corrosion resistance.

\section{Summary}

The crevice corrosion resistance in the high chloride and high acidic solution at high temperature in Ti-15Mo-5Zr and Ti-15Mo-5Zr-1Fe alloys and the tensile properties in $\mathrm{Ti}-$ $15 \mathrm{Mo}-5 \mathrm{Zr}-1 \mathrm{Fe}$ alloy were investigated in this study. It can be concluded that the crevice corrosion resistance linearly increases with the Bo from 2.7900 to 2.8232 in Ti-Mo base alloys. A good combination of strength, ductility and corrosion resistance is obtainable when the Mo equivalency is designed to be between 15.3 and 18.7 mass $\%$ and the Bo is higher than 2.8126 of Ti-15Mo alloy.

\section{REFERENCES}

1) B. Vicentini, D. Sinigaglia and G. Taccani: Corros. Sci. 15 (1975) 479-483.

2) L. A. Yao, F. X. Gan, Y. X. Zhao, C. L. Yao and J. L. Bear: Corrosion 47 (1991) 420-423.

3) D. G. Kolman and J. R. Scully: J. Electrochem. Soc. 140 (1993) 27712779.

4) S. Y. Yu, C. W. Brodrick, M. P. Ryan and J. R. Scully: J. Electrochem. Soc. 146 (1999) 4429-4438.

5) C. S. Brossia and G. A. Cragnolino: Corros. Sci. 46 (2004) 1693-1711

6) N. D. Tomashov, R. M. Altovsky and G. P. Chernova: J. Electrochem. Soc. 108 (1961) 113-119.

7) N. D. Tomashov, G. P. Chernova, Y. S. Ruscol and G. A. Ayuyan: Electrochim. Acta 19 (1974) 159-172.

8) T. Nishimura: J. Power Energy Syst. 2 (2008) 530-537.

9) S. Tamilselvi, T. Nishimura, X. H. Min and K. Tsuzaki: Mater. Trans. 50 (2009) 2545-2551.

10) I. Weiss and S. L. Semiatin: Mater. Sci. Eng. A 243 (1998) 46-65.

11) A. W. Bowen: Scr. Mater. 5 (1971) 709-716.

12) X. H. Min, S. Emura, T. Nishimura, L. Zhang, S. Tamilselvi, K. Tsuchiya and K. Tsuzaki: Mater. Sci. Eng. A 527 (2010) 1480-1488.

13) S. Hanada and O. Izum: Trans. Jpn. Ins. Met. 25 (1986) 755-764.

14) S. Hanada and O. Izumi: Metall. Trans. A 17 (1986) 1409-1420.

15) S. Hanada and O. Izumi: Metall. Trans. A 18 (1987) 265-271.

16) X. H. Min, K. Tsuzaki, S. Emura and K. Tsuchiya: Mater. Sci. Eng. A 528 (2011) 4569-4578.

17) P. J. Bania: Beta Titanium Alloys in 1990's, ed. by D. Eylon, R. R. Boyer and D. A. Koss, (TMS, 1993) pp. 3-14.

18) S. Komatsu and M. Ikeda: Titanium Forum, (ISIJ, Japan, 1997) pp. 2636.

19) S. L. Nyakana, J. C. Fanning and R. R. Boyer: J. Mater. Eng. Perform. 14 (2005) 799-811.

20) M. Morishita, Y. Ashida, M. Chikuda, M. Morinaga, N. Yukawa and H. Adachi: ISIJ Int. 31 (1991) 890-896.

21) S. Y. Yu and J. R. Scully: Corrosion 53 (1997) 965-976.

22) M. Geetha, U. K. Mudali, A. K. Gogia, R. Asokamani and B. Raj: Corros. Sci. 46 (2004) 877-892.

$23)$ D. Q. Martins, W. R. Osório, M. E. P. Souza, R. Caram and A. Garcia: Electrochim. Acta 53 (2008) 2809-2817.

24) M. Morinaga, N. Yukawa, T. Maya, K. Sone and H. Adachi: Sixth World Conference of Titanium, ed. by P. Lacombe, R. Tricot and G. Béranger, (France, 1988) pp. 1601-1606.

25) M. Morinaga, M. Kato, T. Kamimura, M. Fukumoto, I. Harad and K. Kubo: Titanium 92 Science and Technology, ed. by F. H. Froes and I. L. Caplan, (TMS, 1993) pp. 217-224.

26) K. Matsugi, T. Endo, Y. B. Choi and G. Sasaki: Mater. Trans. 51 (2010) 740-748.

27) X. H. Min, S. Emura, T. Nishimura, K. Tsuchiya and K. Tsuzaki: Mater. Sci. Eng. A 527 (2010) 5499-5506.

28) X. H. Min, S. Emura, N. Sekido, T. Nishimura, K. Tsuchiya and K. Tsuzaki: Mater. Sci. Eng. A 527 (2010) 2693-2701. 